\title{
The Use of Engineering Notebooks in an RET Experience
}

\section{Dr. Matthew T. Stimpson, North Carolina State University}

Matthew Stimpson is the Director of Assessment in the Office of Undergraduate Academic Affairs at NC State University.

\section{Dr. Jerome P. Lavelle, North Carolina State University at Raleigh}

Jerome P. Lavelle is Associate Dean of Academic Affairs in the College of Engineering at North Carolina State University. His teaching and research interests are in the areas of engineering economic analysis, decision analysis, project management, leadership, engineering management and engineering education.

\section{Dr. Laura Bottomley, North Carolina State University}

Dr. Laura Bottomley, Teaching Associate Professor of Electrical Engineering and Elementary Education, is also the Director of Women in Engineering and The Engineering Place at NC State University. She has been working in the field of engineering education for over 25 years. She is dedicated to conveying the joint messages that engineering is a set of fields that can use all types of minds and every person needs to be literate in engineering and technology. She is an ASEE and IEEE Fellow and PAESMEM awardee. 


\section{The Use of Engineering Notebooks in an RET Experience}

\section{Introduction}

Laboratory notebooks serve numerous purposes and have been used to document activities, results, success, and revisions [1]. Laboratory notebooks also serve as a means of organizing ideas and serve as a record of legal ownership of ideas [2]. Beyond this, though, notebooks provide valuable information that can be analyzed to answer an array of questions [3]. For instance, laboratory notebooks served as means of understanding how researchers catalog activities [4]. Researchers have also addressed the ways in which lab notebooks are used to document research activities and the degree to which notebooks should be considered vital records [5]. Still others have investigated how implementing electronic notebooks influences laboratory activity [7]. In the education literature science/engineering/STEM notebooks, as distinct from other types of laboratory notebooks, have emerged as a potential approach to enhanced teaching with assessment possibilities. The idea of keeping science notebooks in K-12 classrooms was energized with the publication of the El Centro data [7], which showed that keeping notebooks as a part of inquiry-based science instruction had a strong positive impact on students' writing and language skills. More recent literature has looked at the impacts of engineering notebooks on students' discourse [9].

Because of this emphasis on notebooks in the K-12 classroom and that notebooks are an embedded professional practice of both scientists and engineering, the Grand Challenges for Engineering Focused RET with Stratified Teams program at NC State University incorporated notebooking as a part of the summer program. In this study, we explored how participants in a National Science Foundation (NSF) Research Experience for Teachers (RET) site program used the notebooks that they kept as a part of their participation in laboratories.

\section{RET Program}

The NSF RET program places K-12 teachers in university research labs to broaden their understanding of, experience with, and exposure to engineering research methods and topics. In our particular RET program, we created stratified teams where K-12 teachers, undergraduate education and engineering students, and community college faculty were paired together and engaged in research labs for a six-week summer experience. While the program had many objectives, a principal goal was to provide teachers confidence and then a means to incorporate engineering principles in their teaching of math, science, and technology topics in their classrooms. The formation of stratified teams was a critical component of the program. In total, there were $\mathrm{X}$ labs each with a different research focus, biomechanics, educational computing, sustainable energy, and organic electronic devices.

By creating teams of individuals with different educational and professional backgrounds, we intended to foster cognitive diversity within the groups. Cognitive diversity as a construct is linked with increased outcomes [6]. One such outcome was the development of an engineering informed lesson plan for use by the teachers in their classrooms. Participants in the RET program were engaged in laboratory activities throughout each of the six weeks. In addition, they participated in weekly professional development lunch sessions, industry visits, and worked 
in their teams to create lesson plans tied to their laboratory research activities. Ultimately, the lesson plans were uploaded to "TeachEngineering" to share with the broader K-12 engineering education community.

Laboratory notebooks were provided to all team members to document their RET related activities. The participants were told that keeping the notebooks up to date was an important part of their duties, but they were not given any other instruction as to what should be written in the notebooks. The weekly activities outside of the lab included research tasks, weekly professional development activities, curriculum development sessions, and visits to industry. Some of the professional development activities included ideas for the use of notebooking as a tool in the K12 classroom. Although there has been speculation that STEM notebooks in the classroom could be used as assessment tools, there has been little published work showing how to accomplish this. The RET project decided to look at the teachers' notebooks as potential assessment tools. In order to determine the types of information that could be gleaned from the notebooks, a preliminary study looked at how the teachers used them. The teachers' notebooks were collected at the end of the six-week summer experience and serve as the source of data for this study, which sought to answer the following three research questions:

1. How do participants use research notebooks to record and catalog research activities?

2. How do participants use research notebooks to record and catalog potential pedagogical practices related to using engineering concepts?

3. How do the notebooks reflect participants incorporating engineering concepts into the development of engineering informed lesson plans?

\section{Methods}

From a methods perspective, qualitative procedures were used to address the project research questions. This approach was taken because qualitative methods are better suited to answering questions that are of a how or why nature [10], and for this study, the research questions took that form. Participants in this study were all NSF RET program participants, occurring during a three-year period. For this paper we focus specifically on the participants' laboratory summer activities and curriculum development sessions. Table 1 provides the breakdown of participants by year.

Table 1: Participants

\begin{tabular}{|l|l|}
\hline Participant Type & N \\
\hline Community College Instructors & 11 \\
\hline K-12 Teachers & 14 \\
\hline Undergraduate Education Students & 10 \\
\hline Undergraduate Engineering Students & 24 \\
\hline
\end{tabular}

During the summer RET sessions participants used laboratory notebooks to track their activities in the laboratory, capture details of weekly and team meetings, and to reflect work from their curriculum development sessions. These lab notebooks served as the source of data for this study - there were a total of 48 notebooks across the three years - and they were collected at the 
end of the summer experience. We used thematic analysis of the notebooks to answer the research questions.

Thematic analysis is a common approach for analyzing qualitative data that involves coding, categorizing, and theming to arrive at conclusions. Thematic analysis moves beyond counting and summing code occurrences and relies on the researcher to identifying the ideas in the data [11]. In addition, we used inductive coding, a process that involves coding the raw data without any rior conception of the data. A single member of the research team conducted all coding, which helped to ensure consistency and shared results with other members.

The coding process began by first reflecting on the study's purpose and research questions and reviewing several laboratory notebooks. The purpose of this first step was to develop a broad understanding of how the notebooks were organized. Following this first step, coding began in earnest. The coding process involved the review and reading of a notebook and initially coding data based on research question. Activities detailed and listed, as well as thoughts, reflections, and impressions discussed in the notebook were tied to that research question. Following this a second iteration of coding occurred whereby specific codes were developed. It is important to note that data saturation was achieved after the coding of 20 notebooks. Data saturation is when no new codes emerge from data and continued analysis would yield the same results [12]. To confirm data saturation had been reached, the remaining 28 notebooks were reviewed but were not coded.

We employed data source triangulation to help build the creditability and trustworthiness of findings. Triangulation is the process through which researchers use multiple pieces of evidence to substantiate findings [13]. Data source triangulation was achieved by comparing coded data across the four laboratories and including only those codes there were present across multiple labs. By engaging in this process, we were able to ensure that the coded data used to establish thematic findings were consistent across participants and not simply an artifact of a single individual.

As it relates to the first question on how participants used the lab notebooks to record and catalog research activities, eight codes were developed. Table 2 provides the codes and corresponding definitions.

Table 2: Codes and Definitions for RQ1

\begin{tabular}{|l|l|}
\hline Code & Definition \\
\hline Concerns & Issues expressed related to how laboratory activities are proceeding \\
\hline Diagrams & $\begin{array}{l}\text { Drawings of activities, concepts, and ideas that are related to } \\
\text { laboratory activities }\end{array}$ \\
\hline Directions & List of steps to follow in the laboratory \\
\hline Frustrations & $\begin{array}{l}\text { Expressions of annoyance at the inability to accomplish a laboratory } \\
\text { task or activity }\end{array}$ \\
\hline Impressions & Feelings and thoughts related to laboratory activities \\
\hline Learning & $\begin{array}{l}\text { Skills, abilities, and habits of mind acquired through the course of the } \\
\text { laboratory experience }\end{array}$ \\
\hline Results & Results of laboratory exercises and experiments \\
\hline
\end{tabular}


The second research question addressed how participants use research notebooks to record and catalog potential pedagogical practices related to using engineering concepts, and seven researcher developed codes relate to this question:

Table 3: Codes and Definitions for RQ2

\begin{tabular}{|l|l|}
\hline Code & Definition \\
\hline Concepts & Ideas and general notions \\
\hline Design Process & The engineering design process \\
\hline Engineering & What engineering is \\
\hline Ideas & Thought for an activity, concept, or future point for consideration \\
\hline Notes & Catalog of discussion, ideas, and activities \\
\hline Topics & Listing of points discussed \\
\hline Visits & Record of industry visit, what was observed and discussed \\
\hline
\end{tabular}

Finally, the codes for the last research question which focuses on how the notebooks reflect participants incorporating engineering concepts into the development of engineering informed lesson plans are provided in Table 4.

Table 4: Codes and Definitions for RQ3.

\begin{tabular}{|l|l|}
\hline Code & Definition \\
\hline Documenting & A record of activities \\
\hline Evolution of Ideas & $\begin{array}{l}\text { Discussion and presentation of the progression of a single idea or } \\
\text { ideas }\end{array}$ \\
\hline Ideas & Thought for an activity \\
\hline Listing & A collection of activities or steps \\
\hline Sketches & $\begin{array}{l}\text { Drawings of activities, concepts, and ideas that were related to } \\
\text { curriculum development }\end{array}$ \\
\hline Standards & State standards for curriculum \\
\hline
\end{tabular}

At the conclusion of the coding process, theming was conducted. During theming, codes were categorized together to reach thematic conclusions regarding our research questions. We present the themes and evidence of the themes in the results section.

Results

Having coded and analyzed the data, we identified themes around each research question. We present these themes organized by research question, though there is some thematic overlap. We start with the first research question focused on the use of the notebooks in laboratory activities. The eight established codes were collapsed into three thematic findings: Achievements, emotional response, and research activities. Table 5 provides the list of codes and themes. 
Table 5: Thematic Findings Related to RQ1.

\begin{tabular}{|l|l|}
\hline Theme & Codes \\
\hline Achievements & Learning \\
& Successes \\
\hline Emotional Response & Concerns \\
& Frustrations \\
& Impressions \\
\hline Research Activities & Diagrams \\
& Directions \\
& Results \\
\hline
\end{tabular}

The first theme, "achievements", centers around the notion that participants used their lab notebooks to document what they accomplished in the laboratory in terms of learning and successes. We observed multiple instances of participants acknowledging new knowledge they have gained, new concepts that they have been introduced to, and new approaches to problems.

For instance, in one laboratory setting multiple participants documented the way in which they were taught to review a journal article, noting that "the procedures section" was a critical component needed in the review. Meanwhile, participants in a laboratory focused on biomechanics details extensively — new knowledge related to biomechanics and anatomy. Collectively, the data related to this theme document that participants were exposed to new information, and they cataloged much of this information in the notebooks. Yet, for many participants, they encountered repeated frustrations and difficulties.

Our second thematic finding relates to the descriptions present in many notebooks that focus on concerns, frustrations, and impressions that participants encountered. Participants were prompted to write reflections in their notebooks, and many documented their feelings and emotions related to the experience. We have labeled this thematic finding "emotional responses," as the comments reflect participants attempt to process the emotions and immediate reactions to the happenings in the lab.

For instance, many participants discussed their frustrations over not being able to quickly and easily comprehend what was happening in the lab. One participant discussed, multiple times, a feeling of being inadequate compared to the abilities of others in the laboratory. Still others documented repeated attempts at trying to understand how to use specific software or laboratory tools.

We labeled the final thematic finding related to the first research question "research activities." This finding is not particularly surprising, given the time spent in research laboratories and that laboratory notebooks served as means of documenting tasks in the lab. Many participants' notebooks documented the activities performed in the laboratory, findings from the research laboratory, and evolution of laboratory activities.

We also observed consistency among notebooks from common labs. For instance, in the laboratory that focused on biomechanics, participants routinely documented sketches of joints 
and data points arising from experiments. Across all the laboratories, we see the commonality of activities being documented and data from those activities being documented.

We developed three themes for the second research question, how participants use research notebooks to record and catalog potential pedagogical practices related to using engineering concepts. Table 6 presents each thematic finding and its corresponding codes.

Table 6: Thematic Findings Related to RQ2

\begin{tabular}{|l|l|}
\hline Theme & Codes \\
\hline Activities & Notes \\
& Topics \\
& Visits \\
\hline Understanding Engineering & Design Process \\
& Engineering \\
\hline Learning & Concepts \\
& Ideas \\
\hline
\end{tabular}

The finding "activities" reflects participants use of the notebooks to detail what was done during the curriculum development sessions. Here the participants made note of speakers and topics covered, they constructed notes outlining the subject matter discussed, and also cataloged and annotated industry visits that occurred.

Many of our participants entered the RET program lacking a breadth and depth of understanding engineering. We exposed them to the broad nature of engineering by contextualizing engineering for them, exposing them to industry, and covering the engineering design process. Consequently, participants catalog in their notebooks an understanding of engineering, and our second finding, understanding of engineering reflects participants' notation of what engineering is. For instance, participants document a definition of engineering, and participants describe the engineering design process. Given the broader purpose of the RET was to foster the use of engineering concepts and principles in the teaching of math, science, and technology, it was critical that we provided participants a conceptual understanding of engineering.

The final theme reflected in the data tied to this research question is "learning." Participants documented concepts and ideas learned and discussed during the curriculum development sessions. This includes ways to approach teaching and resources available to them. Some participants documented ideas and ways of incorporating concepts learned into the classrooms. Others made note of new resources they were exposed to, such as Teach Engineering. This final theme focused exclusively on data related to participant learning as it relates to the development of engineering informed lesson plans.

Data for the final research question about how participants incorporated engineering concepts into the development of engineering informed lesson plans yielded two themes: "Cataloging information" (included codes documenting, listing, and standards) and "curriculum planning" (included codes evolution of ideas, ideas, and sketches). It is important to note data were very thin for this particular research question. 
Participants did catalog information needed to construct lesson plans, including listing of state education standards, documenting what the activity might be, and even brainstorming and listing possible options. In addition, there was some evidence to suggest laboratory notebooks were used for curriculum planning. Some participants documented the evolution of ideas related to the development of the lesson plan. Sketches were also present that illustrated the activity in which students would engage in.

However, there was not an overwhelming amount of evidence to illustrate that the laboratory notebooks were a critical component of lesson planning. In many instances, there was no evidence of the use of notebooks for this purpose. This is a unique aspect of the data related to this research question, and we more fully explore this issue in the discussion section.

\section{Discussion}

The laboratory notebooks we analyzed provided a tremendous amount of data, especially related to the first and second research question. Data and the resulting findings were most robust on the question of how participants used the notebooks to record and catalog research activities, and this should come as no surprise. Laboratory notebooks have a natural connection to the lab exercises and using the notebooks to record research activities reflected this fact. In this regard, participants used the notebooks in ways that would be expected. Directions, trials, and results are all detailed in the notebooks. There was also some commonality between participants' notebooks who were in the same lab experience. Similar types of information were recorded. Other instances saw the same type of structure and format to the notebook, not only in content but in how the content was organized. Consequently, the thematic findings related to the first research question are consistent with the literature and the purpose of notebooks in laboratory settings [1], [2]. Notebooks serve as the means through which participants cataloged their activities in the laboratory and constitute a record of what the participants were exposed to during the summer RET experience. As an example, beyond the data related to research activities, the notebooks also served as a means through which the participants expressed frustrations. This took the form of documenting difficulties with laboratory equipment, potential flaws in experiments, and even team dynamics. There was also evidence of self-doubt, and some participants noted feeling lost and confused about lab activities.

In terms of the second research question, the data suggest that participants used the notebooks to document the topics covered during professional development exercises, which were largely designed to expose participants to pedagogical practices incorporating engineering concepts in the teaching of math, science, and engineering. The data demonstrated that participants noted key ideas being discussed and some documented potential avenues to explore.

The disaggregated data related to the second research question coincided with the planned professional development activities. Thematically, however, the data represent a snap shot of what participants were exposed to, pedagogically, and data also represent participants attempts at learning and synthesizing information. The data begin to get thin when transferring the pedagogical knowledge and discussion to an actual curriculum. 
On the question of the third research question, we know that curriculum development occurred, as all teams had to submit a curriculum plan to "TeachEngineering" as part of the program. We were hopeful that we would find the notebooks serving as a source of information related to the development of the curriculum plans and, for the most part, that was not the case. While some data related to this research question existed, it was not robust, detailed, or particularly insightful. The vast majority of participants did not document any curriculum development plans in their laboratory notebook. Participants who did document curriculum development did so in a manner that lacked specificity. The lack of information could be due to several reasons.

First, laboratory notebooks could be the wrong way to record curriculum development. While notebooks are common occurrence in research settings, laboratory notebooks are not the predominate way in which curriculum is developed and refined. Second, the laboratory notebooks lacked the specific structure that is common with most lesson plans. State standards, learning activities, outcomes, and means of assessment are common elements found in lesson plans. Participants could have outlined all of these aspects in their notebooks and had to do so for the "TeachEngineering" curriculum, but the notebooks lacked prompts and salient topical areas to which the participants could respond. Finally, while participants were instructed to use the laboratory notebooks to record all grant-related activities, a lack of comprehensive and consistent training in the use the notebooks, specifically for curriculum development, was not provided across the various laboratory groups.

\section{Future Considerations}

From our experiences in this NSF RET we believe that laboratory notebooks can provide a strong source of data for individuals interested in incorporating them into the research process, and we suggest the following be considered. First, it is important that timely and consistent training be given on the use laboratory notebooks, how they can and should be structured, and their overall use in the research process. Second, care should be given when participants may be unfamiliar with the use of laboratory notebooks. While notebooks are common place in many fields, the use of notebooks is less common in education settings. To that end, projects involving individuals from the social sciences may need to be particularly introduced to the use of laboratory notebooks. Finally, it is critical that participants understand how the notebooks will be used after the fact, and ensure that training covers expectations. In our project, there would have been room for participants to include iterations of lesson plans into the notebooks, but it should not be assumed that participants would do so on their own. 
References

1. S. Y. Nussbeck, P. Weil, J. Menzel, B. Marzec, K. Lorberg, and B. Schwappach. "The laboratory notebook in the $21^{\text {st }}$ century". EMBO Reports, vol. 15, pp. 633-634, 2015.

2. S. Schnell, "Ten simple rules for a computational biologists laboratory notebook". Computational Biology, Vol. 11, no. 9, September, 2015. [Online]. Available: http://europepmc.org/backend/ptpmcrender.fcgi?accid=PMC4565690\&blobtype=pdf. [Accessed Jan. 25, 2020].

3. C. D. Christ, M. Zentgraf, and J. M. Krieg, "Mining electronic laboratory notebooks: Analysis, retrosynthesis, and reaction based enumeration". Journal of Chemical Information and Modeling, vol. 52, pp. 1745-1756, 2012.

4. P. R. E. dos Santos, R. S. Borges, and F. dos Santos Lourenco. "Archival documents produced by scientific work: An analysis of laboratory notebooks from the Instituto Oswaldo Cruz". Historia Ciencias Saude-Manguinhos, vol. 26, pp. 1013-1025, 2019

5. P. Calvert. "Should all lab books be treated as vital records? An investigation into the use of lab books by research scientists. Australian Academic \& Research

6. S. Horwitz and I. B. Horwitz, "The effects of team diversity on team outcomes: A metaanalytic review of team demography”. Journal of Management, vol. 33, pp. 987-1015, 2007

7. J. Zeng, M. Hillman, and M. Arnold. "Impact of the implementation of a well-design electronic laboratory notebook on bioanalytical laboratory function. Bioanalysis, vol. 3, 1501-1511, 2011.

8. O. M. Amaral, L. Garrison, \& M. Klentschy (2002) Helping English Learners Increase Achievement Through Inquiry-Based Science Instruction. Bilingual Research Journal, 26:2, 213-239, DOI: $\underline{10.1080 / 15235882.2002 .10668709}$

9. J. D. Hertel, C. M. Cunningham, \& G. J. Kelly (2017) The roles of engineering notebooks in shaping elementary engineering student discourse and practice, International Journal of Science Education, 39:9, 1194-1217, DOI: 10.1080/09500693.2017.1317864

10. R. K. Yin. Case study research: Design and methods. Thousand Oaks, CA: Sage Publications, Inc., 2012.

11. G. Guest, K. M. MacQueen, and E. E. Namey. Applied thematic analysis. Thousand Oaks, CA: Sage Publications, Inc., 2012.

12. P. I. Fusch and L. R. Ness. "Are we there yet? Data saturation in qualitative research". The qualitative report, vol. 20, pp. 1408-1416, 2015. 
13. N. K. Denzin. The research act: A theoretical introduction to sociological methods. New York: Praeger, 1978. 